\title{
Scientific Protocol Title
}

National Cancer Institute

\section{Source}

National Cancer Institute. Scientific Protocol Title. NCI Thesaurus. Code C132350.

The descriptive name of the protocol that is intended for medical professionals, and which is written using medical and scientific language. 